\title{
Awal Mula dan Rutinitas Bersepeda Tidak Mempengaruhi Indeks Massa Tubuh (IMT)
}

\author{
Muhammad Fadhol Romdhoni ${ }^{1}$, Yuhantoro Budi Handoyo Sakti ${ }^{2}$, Dewi Karita ${ }^{3}$ \\ ${ }^{1}$ Bagian Farmakologi, Fakultas Kedokteran, Universitas Muhammadiyah Purwokerto \\ ${ }^{2}$ Bagian Bedah, Fakultas Kedokteran, Universitas Muhammadiyah Purwokerto \\ ${ }^{3}$ Bagian Biokimia, Fakultas Kedokteran, Universitas Muhammadiyah Purwokerto \\ Email: fadhol.romdhoni@gmail.com
}

\begin{abstract}
Research in Semarang $9.1 \%$ and $10.6 \%$ of children aged 6-7 years, suffered from overweight and obesity, with the ratio of boys are higher than girls. Lifestyle changes is the first step to regulate body mass index back to normal. Healthy active lifestyle is now being campaigned, one of exercises that recently famous is biking. This research is to find out the relationship between time baseline with IMT and biking routine with IMT. This study is a one group survey without a control design. The method used in this study is a cross sectional survey. Respondents are biker who agreed to participated in this study. This study was conducted of 173 respondents. Non-parametric statistical analysis test using Kolmogorov smirnov (alternative test of chi square reasons the data does not meet the requirements). Data on the relationship between time baseline and BMI was $\mathrm{p}=0.654(\mathrm{p}>0.05)$, shows that time baseline is not related with body mass index (BMI) values. Furthermore, the relationship of biking routines with BMI was $p=0.376(p>0.05)$, which is not related between biking routines and body mass index (BMI) values. In conclusion, that time baseline and biking routines have no relationship to the body mass index value, as one of obesity indicator.
\end{abstract}

Key word: biking, body mass index (BMI), exercise

\section{Abstrak}

Penelitian di Semarang 9,1\% dan 10,6\% anak usia 6-7 tahun, berturut turut menderita overweight dan obesitas, dengan proporsi laki-laki lebih besar dibanding perempuan. Perubahan gaya hidup merupakan langkah awal untuk memperbaiki indeks massa tubuh menuju normal. Gaya hidup berolah raga saat ini semakin banyak dilakukan, salah satu yang dipilih adalah bersepeda. Penelitian ini bertujuan untuk mengetahui hubungan antara awal mula bersepeda dengan IMT dan rutinitas bersepeda dengan IMT. Jenis penelitian yang digunakan dalam penelitian ini adalah survei one group without control design. Metode pendekatan yang digunakan dalam penelitian ini adalah survei cross sectional. Responden merupakan peserta aktifitas olah raga bersepeda yang bersedia sebagai responden penelitian ini. Jumlah respondennya adalah 173 orang. uji analisis statistik non parametrik menggunakan Kolmogorov smirnov (uji alternatif dari chi square sebab datanya tidak memenuhi syarat). Data tentang hubungan awal mula bersepeda dengan IMT diperoleh $\mathrm{p}=0,654$ ( $\mathrm{p}>0,05)$, bermakna bahwa tidak terdapat hubungan yang signifikan antara awal mula bersepeda dengan nilai indeks massa tubuh (IMT). Selanjutnya data tentang hubungan rutinitas bersepeda dengan IMT diperoleh $\mathrm{p}=0,376$ ( $\mathrm{p}>0,05)$, bermakna bahwa tidak terdapat hubungan yang signifikan antara rutinitas bersepeda dengan nilai indeks massa tubuh (IMT). Disimpulkan bahwa awal mula bersepeda yang menunjukkan lamanya seseorang melakukan bersepeda dan rutinitas bersepeda tidak memiliki hubungan yang signifikan terhadap nilai indeks massa tubuh (IMT), yang merupakan salah satu indikator obesitas.

Kata Kunci: bersepeda, indeks massa tubuh (IMT), berolah raga

\section{Pendahuluan}

Kebugaran jasmani merupakan potensi besar yang harus dimiliki oleh setiap manusia agar dapat beraktivitas dengan maksimalsehingga pencapaian dapat lebih optimal. Dengan kebugaran jasmani yang rendah tentuakan sangat mempengaruhi kinerja seseorang seperti halnya bekerja sedikit tubuh sudah merasa capek disertai rasa kantuk. Berbeda dengan orang yang memiliki tubuh yang bugar yang mampu bekerja secara fulltime dengan penuh semangat dan menghasilkan sesuatu yang maksimal. Kebugaran jasmani adalah kemampuan untuk melakukan kegiatan sehari-hari tanpa merasakan kelelahan yang berlebihan, serta masih memiliki cadangan tenaga untuk mengisi waktu luang dan kegiatan-kegiatan yang bersifat mendadak ${ }^{1}$. Jalan- 
jalan dan bersepeda termasuk intensitas sedang, dan jika dilakukan secara teratur, dapat mengakibatkan pengeluaran energi dalam jumlah besar ${ }^{2}$.

Penelitian di Amerika pada tahun 1997, 21\%-24\% anak Amerika menderita overweight dan $15 \%$ menderita obesitas. Penelitian di Rusia 6\% overweight dan $10 \%$ obesitas, di China 3,6\% overweight dan 3,4\% obesitas. Di Singapura pada tahun 2000 didapatkan prevalensi obesitas anak umur 6-7 tahun 10,8\%,2 sedangkan di Indonesia angka kejadian obesitas belum diketahui dengan pasti. Prevalensi obesitas pada anak SD di beberapa kota besar di Indonesia berkisar 2,1\%-25\% . Penelitian di Semarang 9,1\% dan 10,6\% anak usia 6-7 tahun, berturut turut menderita overweight dan obesitas, dengan proporsi laki-laki lebih besar dibanding perempuan $^{34}$.

Perubahan gaya hidup merupakan langkah awal untuk memperbaiki indeks massa tubuh menuju normal. Gaya hidup berolah raga saat ini semakin banyak dilakukan, salah satu yang dipilih adalah bersepeda hingga banyak yang menekuni hingga menjadi atlet sepeda, bahkan berprestasi di kancah nasional maupun internasional ${ }^{5}$.

\section{Metode}

Jenis penelitian yang digunakan dalam penelitian ini adalah survei one group without control design. Metode pendekatan yang digunakan dalam penelitian ini adalah survei cross sectional. Responden merupakan peserta aktifitas olah raga bersepeda yang bersedia sebagai responden penelitian ini. Jumlah respondennya adalah 173 orang. Data yang dikumpulkan merupakan data primer yang diperoleh dengan cara mengukur antropometri dan anamnesis. Varibel yang diukur adalah awal mula beraktifitas bersepeda, rutinitas bersepeda, dan indeks massa tubuh (IMT).

Dalam penelitian ini peneliti melakukan analisis univariat untuk memperoleh gambaran setiap variabel, distribusi frekuensi berbagai variabel yang diteliti baik variabel independen maupun variabel dependen. Dengan melihat distribusi frekuensi dapat diketahui deskripsi dari masing-masing variabel yang meliputi kebiasaan makan, aktivitas fisik dan indeks massa tubuh mahasiswa juga variabel lain yang mungkin berpengaruh terhadap hasil penelitian seperti karakteristik responden. Analisis bivariat dilakukan untuk mengetahui ada tidaknya hubungan antara variabel independen dengan variabel dependen. Uji statistik yang digunakan adalah Kolmogorov smirnov dengan tabel 2xk (tabel 2x4).

\section{Hasil}

Karakteristik responden

Dari 173 responden terdiri dari 157 responden $(90,8 \%)$ laki-laki dan 16 responden $(9,2 \%)$ perempuan seperti yang terlihat pada tabel 1 berikut ini:

Tabel 1. Karakteristik responden

\begin{tabular}{lc}
\hline Jenis Kelamin & Nilai \\
\hline laki-laki & $90,8 \%(157)$ \\
\hline perempuan & $9,2 \%(16)$ \\
\hline \multicolumn{1}{c}{ Total } & $100 \%(173)$ \\
\hline
\end{tabular}

Distribusi usia dari responden paling muda adalah berusia 25 tahun dan paling tua berusia 71 tahun, seperti yang tampak pada tabel 2 .

Tabel 2. Usia responden

\begin{tabular}{lc}
\hline & Usia (Tahun) \\
\hline Minimum & 25 \\
\hline Median & 50 \\
\hline Maksimum & 71 \\
\hline
\end{tabular}

Awal mula aktifitas bersepeda dari reponden dibagi menjadi 2 kelompok yakni kelompok yang memulai aktifitas bersepeda $\leq 3$ tahun yang lalu dan $>3$ tahun yang lalu. Sebanyak $63(36,4 \%)$ responden memulai aktifitas bersepeda $\leq 3$ tahun yang lalu dan sebanyak 110 $(63,6 \%)$ responden memulai aktifitas bersepeda $>3$ tahun yang lalu, seperti yang tampak pada tabel tabel 3 berikut ini

Tabel 3. Awal mula bersepeda

\begin{tabular}{cc}
\hline Awal Mula & Nilai \\
\hline$\leq 3$ tahun yang lalu & $36,4 \%(63)$ \\
\hline$>3$ tahun yang lalu & $63,6 \%(110)$ \\
\hline Total & $100 \%(173)$ \\
\hline
\end{tabular}

Rutinitas bersepeda dari reponden dibagi menjadi 2 kelompok yakni kelompok yang bersepeda $\leq 3 \mathrm{x} /$ pekan dan > 3 x/pekan. Sebanyak $63(36,4 \%)$ responden memulai aktifitas bersepeda $\leq 3$ tahun yang lalu dan sebanyak $110(63,6 \%)$ responden memulai aktifitas bersepeda $>3$ tahun yang lalu, seperti yang tampak pada tabel tabel 4 berikut ini

Tabel 4. Rutinitas bersepeda

\begin{tabular}{cc}
\hline Rutinitas bersepeda & Nilai \\
\hline$\leq 3$ kali per pekan & $71,7 \%(124)$ \\
\hline$>3$ kali per pekan & $28,3 \%(49)$ \\
\hline Total & $100 \%(173)$ \\
\hline
\end{tabular}

Indeks massa tubuh (IMT) dari responden digolongkan dalam 4 kategori yaitu berat badan kurang, normal, 
kelebihan berat badan, dan obesitas. Sebanyak $2(1,2 \%)$ responden tergolong berat badan kurang, 89 (51,4\%) responden tergolong normal, $73(42,3 \%)$ responden tergolong kelebihan berat badan, dan $9(5,2)$ responden tergolong obesitas. Hal tersebut sesuai dengan yang terlihat pada tabel 5 berikut ini

Tabel 5. Nilai indeks massa tubuh (IMT)

\begin{tabular}{lc}
\multicolumn{1}{c}{ IMT } & Nilai \\
\hline Berat badan kurang & $1,2 \%(2)$ \\
\hline Normal & $51,4 \%(89)$ \\
\hline Kelebihan berat badan & $42,3 \%(73)$ \\
\hline Obesitas & $5,2 \%(9)$ \\
\hline \multicolumn{1}{c}{ Total } & $100 \%(173)$ \\
\hline
\end{tabular}

Dari data tersebut, selanjutnya dilakukan uji statistik untuk mengetahui korelasi antara awal mula aktifitas bersepeda dengan indeks massa tubuh (IMT) dan korelari antara rutinitas bersepeda dengan indeks massa tubuh (IMT). Uji statistik menggunakan uji non parametrik alternative dari chi square yaitu uji Kolmogorov smirnov karena pada penelitian ini memunculkan tabel kontingensi $2 \times 4$, seperti yang tampak pada tabel 6 dan tabel 7 berikut ini.

Tabel 6. Hubungan awal mula bersepeda dengan indeks massa tubuh (IMT)

\begin{tabular}{|c|c|c|c|c|}
\hline \multirow{2}{*}{$\begin{array}{l}\text { Indeks } \\
\text { Massa } \\
\text { Tubuh }\end{array}$} & \multicolumn{2}{|c|}{ Awal Mula } & \multirow[t]{2}{*}{ Jumlah } & \multirow{2}{*}{$\begin{array}{c}\mathbf{p} \\
\text { value }\end{array}$} \\
\hline & $\begin{array}{c}\leq 3 \\
\text { tahun }\end{array}$ & $\begin{array}{c}>3 \\
\text { tahun }\end{array}$ & & \\
\hline BB Kurang & 0 & 2 & 2 & \multirow{5}{*}{0,654} \\
\hline Normal & 29 & 60 & 89 & \\
\hline BB Lebih & 29 & 44 & 73 & \\
\hline Obesitas & 5 & 4 & 9 & \\
\hline Total & 63 & 110 & 173 & \\
\hline
\end{tabular}

Tabel 7. Hubungan rutinitas bersepeda dengan indeks massa tubuh (IMT)

\begin{tabular}{|c|c|c|c|c|}
\hline \multirow{2}{*}{$\begin{array}{l}\text { Indeks } \\
\text { Massa } \\
\text { Tubuh }\end{array}$} & \multicolumn{2}{|c|}{ Rutinitas } & \multirow[t]{2}{*}{ Jumlah } & \multirow{2}{*}{$\underset{\text { value }}{\mathbf{p}}$} \\
\hline & $\begin{array}{l}\leq 3 \mathrm{x} / \\
\text { pekan }\end{array}$ & $\begin{array}{l}>3 \mathrm{x} / \\
\text { pekan }\end{array}$ & & \\
\hline BB Kurang & 3 & 0 & 2 & \multirow{5}{*}{0,376} \\
\hline Normal & 61 & 28 & 89 & \\
\hline BB Lebih & 53 & 20 & 73 & \\
\hline Obesitas & 8 & 1 & 9 & \\
\hline Total & 124 & 49 & 173 & \\
\hline
\end{tabular}

\section{Diskusi}

Data penelitian di atas dimasukkan dalam tabel kontingensi 2 x k yaitu tabel 2 x 4, selanjutnya dilakukan uji analisis statistik non parametrik menggunakan Kolmogorov smirnov (uji alternatif dari chi square sebab datanya tidak memenuhi syarat). Data tentang hubungan awal mula bersepeda dengan IMT diperoleh $\mathrm{p}$ $=0,654(\mathrm{p}>0,05)$, bermakna bahwa tidak terdapat hubungan yang signifikan antara awal mula bersepeda dengan nilai indeks massa tubuh (IMT). Selanjutnya data tentang hubungan rutinitas bersepeda dengan IMT diperoleh $\mathrm{p}=0,376$ ( $\mathrm{p}>0,05)$, bermakna bahwa tidak terdapat hubungan yang signifikan antara rutinitas bersepeda dengan nilai indeks massa tubuh (IMT). Nilai IMT yang tinggi menyebabkan tingkat kesegaran yang rendah sehingga akan membuat orang untuk menurunkannya dengan melakukan aktifitas fisik ${ }^{6}$.

Hasil tersebut mendukung penelitian yang pernah dilakukan sebelumnya yang menyatakan bahwa tidak terdapat perbedaan IMT bermakna berdasarkan tingkat jenis dan tingkat aktivitas fisik. 7893 . Penelitian yang dilakukan di Eropa, Amerika Utara, dan Autralia juga menunjukkan tidak adanya hubungan antara aktifitas bersepeda dengan obesitas yang salah satu indikatornya digunakan nilai $\mathrm{IMT}^{2}$. Hal tersebut juga didukung oleh penelitian yang pernah dilakukan di Semarang, yang merupakan wilayah di propinsi yang sama dengan penelitian ini, yang menunjukkan bahwa tidak ada hubungan yang signifikan antara aktifitas bersepeda dengan indeks massa tubuh ${ }^{8}$.

Pada penelitian lain justru bertolak belakang dengan hasil data tersebut yaitu menyatakan bahwa aktifitas fisik berhubungan dengan nilai IMT ${ }^{10} 111213$. Dengan IMT yang normal maka akan dapat menigkatkan daya tahan kardiovaskuler ${ }^{14} 15$.

Kebugaran jasmani dapat diperoleh dengan perencanaan sistematik melalui pemahaman tentang penerapan pola hidup sehat yang meliputi makan, istirahat dan berolahraga. Olahraga yang dianjurkan untuk menjaga kebugararan adalah oalahraga yang bersifat aerobik, salah satu contohnya adalah bersepeda ${ }^{1}{ }^{16}$. Untuk memperoleh nilai IMT yang normal, selain melakukan aktifitas fisik juga diharuskan untuk mengatur pola makan. Pola makan yang baik dapat membantu untuk mencapai nilai IMT yang normal ${ }^{17} 18$.

\section{Simpulan}

Berdasarkan data penelitian serta pembahasan maka dapat disimpulkan bahwa awal mula bersepeda yang menunjukkan lamanya seseorang melakukan bersepeda dan rutinitas bersepeda tidak memiliki hubungan yang signifikan terhadap nilai indeks massa tubuh (IMT), yang merupakan salah satu indikator obesitas. Untuk menurunkan IMT, hal yang harus dilakukan tidak hanya melakukan aktifitas bersepeda namun juga memperhatikan pola makan, pola tidur, pengeloaan stress, dan lain-lain. 


\section{Pengakuan / Conflict of interest}

Peran masing-masing author:

- Muhammad Fadhol Romdhoni

Menyusun laporan dan analisis data serta uji statistik

- Yuhantoro Budi Handoyo Sakti

Pengambilan data dan penyajian data

- Dewi Karita

Analisis data, uji statistik, dan translate ke Bahasa inggris

Penelitian dan penerbitan artikel ini tidak memiliki conflict of interest dengan pihak manapun.

\section{Referensi}

1. Arjuna F. MENJAGA KEBUGARAN JASMANI DENGAN BERSEPEDA. 2009:125.

2. Bassett DR, Pucher J, Buehler R, Thompson DL, Crouter SE. Walking, cycling, and obesity rates in Europe, North America and Australia. J Phys Act Heal. 2008;5(6):795-814. doi:10.1123/jpah.5.6.795

3. Ekoparman B, Widajadnja N, Program M, et al. Hubungan Antara Indeks Massa Tubuh Dengan Tingkat Kebugaran Jasmani Mahasiswa Program Studi Pendidikan Dokter Universitas Tadulako Tahun Masuk 2012. J Ilm Kedokt. 2015;2(3).

4. Ismail M, CL. T. Prevalence of obesity in Malaysia. In: The Asia-Pacific perspective: redefining obesity and its treatment. Geneva, Switz World Heal Organ. 2000:56. doi:09577082-1-1

5. Nurhidayah PS. Jurnal Keolahragaan. $J$ Keolahragaan. 2015;3(April):66-78.

6. Utari A. Tingkat Kesegaran Jasmani Pada Anak Usia 12-14 Tahun. Dr Diss Progr Pascasarj Univ Diponegoro. 2007:86. http://eprints.undip.ac.id/16285/.

7. Candrawati S. Hubungan Tingkat Aktivitas Fisik Dengan Indeks Massa Tubuh (IMT) Dan Lingkar Pinggang Mahasiswa. Soedirman J Nurs. 2011;6(2):112-118.

8. Lestari A, Herawati I, Wahyuni. Hubungan antara indeks massa tubuh (IMT) dan aktivitas fisik dengan tingkat kebugaran pada anak usia 10-12 tahun. Skripsi Ilmu Kesehat / Progr Stud D IV Fisioter Jenis. 2012:1-12.

9. Nugroho K, Mulyadi N, Masi GNM. Hubungan Aktivitas Fisik Dan Pola Makan Dengan Perubahan Indeks Massa Tubuh Pada Mahasiswa Semester 2 Programstudi Ilmu Keperawatan Fakultas Kedokteran. $J$ Keperawatan. 2016;4(2).

10. Ridwan E. Ethical Use of Animals in Medical Research. J Indones Med Assoc. 2013;(Vol. 63
No. 3 March 2013).

http://indonesia.digitaljournals.org/index.php/i dnmed/article/view/1237.

11. Nia Novita Wirawan. Indonesian Journal of Human Nutrition. Indones J Hum Nutr. 2018;1(1):14-22. doi:10.21776/ub.ijhn.2016.003.Suplemen.5

12. Brown BB, Smith KR, Hanson H, Fan JX, Kowaleski-Jones L, Zick CD. Neighborhood design for walking and biking: Physical activity and body mass index. Am J Prev Med. 2013;44(3):231-238.

doi:10.1016/j.amepre.2012.10.024

13. Menai M, Charreire H, Galan P, et al. Differential Associations of Walking and Cycling with Body Weight, Body Fat and Fat Distribution - The ACTI-Cités Project. Obes Facts. 2018;11(3):221-231. doi:10.1159/000488532

14. Febriyanti NK, Adiputra IN, Sutadarma IWG. HUBUNGAN INDEKS MASSA TUBUH DAN AKTIVITAS FISIK TERHADAP DAYA TAHAN KARDIOVASKULAR PADA MAHASISWA FAKULTAS KEDOKTERAN UNIVERSITAS UDAYANA. 2015;831.

15. Marlina Y, Huryati E, Soenarto Y. Indeks massa tubuh dan aktivitas fisik dengan tekanan darah pada pelajar SMA. J Gizi Klin Indones. 2016;12(4):160. doi:10.22146/ijen.23308

16. Syauqy A. Hubungan Indeks Massa Tubuh dengan Kebugaran Jasmani Mahasiswa Prodi Kedokteran UNJA. Jambi Med J. 2017;5(1):87-93.

17. Faizah I, Muniroh L. Analisis Perubahan Berat Badan, Indeks Massa Tubuh dan Persentase Lemak Tubuh Klien Pasca Pemberian Diet South Beach pada My Meal Catering Surabaya Analysis of Body Weight Change , Body Mass Index and Percentage of Body Fat Clients Post South Beach Diet. J Gizi Indones. 2018;2(1):52-58. doi:10.20473/amnt.v2.i1.2018.52-58

18. Madaliana NA, Rahfiludin MZ, Aruben R. HUBUNGAN ASUPAN GIZI DAN AKTIVITAS FISIK DENGAN INDEKS MASSA TUBUH MENURUT UMUR (IMT/U) PADA ANAK JALANAN (Studi Kasus Rumah Pintar Bang Jo PKBI Jawa Tengah di Kawasan Pasar Johar Kota Semarang Tahun 2018). J Kesehat Masy. 2018;6(2):49-56. 